\title{
Organic-Inorganic Perovskite Light-Emitting Electrochemical Cells with a Large Capacitance
}

\author{
Huimin Zhang, Hong Lin, Chunjun Liang,* Hong Liu, Jingjing Liang, Yong Zhao, \\ Wenguan Zhang, Mengjie Sun, Weikang Xiao, Han Li, Stefano Polizzi, Dan Li, \\ Fujun Zhang, Zhiqun He,* and Wallace C. H. Choy*
}

While perovskite light-emitting diodes typically made with high work function anodes and low work function cathodes have recently gained intense interests. Perovskite light-emitting devices with two high work function electrodes with interesting features are demonstrated here. Firstly, electroluminescence can be easily obtained from both forward and reverse biases. Secondly, the results of impedance spectroscopy indicate that the ionic conductivity in the iodide perovskite $\left(\mathrm{CH}_{3} \mathrm{NH}_{3} \mathrm{Pbl}_{3}\right)$ is large with a value of $\approx 10^{-8} \mathrm{~S} \mathrm{~cm}^{-1}$. Thirdly, the shift of the emission spectrum in the mixed halide perovskite $\left(\mathrm{CH}_{3} \mathrm{NH}_{3} \mathrm{Pbl}_{3-x} \mathrm{Br}_{x}\right)$ light-emitting devices indicates that $\mathrm{I}^{-}$ions are mobile in the perovskites. Fourthly, this work shows that the accumulated ions at the interfaces result in a large capacitance $\left(\approx 100 \mu \mathrm{F} \mathrm{cm}^{-2}\right)$. The above results conclusively prove that the organic-inorganic halide perovskites are solid electrolytes with mixed ionic and electronic conductivity and the light-emitting device is a light-emitting electrochemical cell. The work also suggests that the organic-inorganic halide perovskites are potential energy-storage materials, which may be applicable in the field of solid-state supercapacitors and batteries.

\section{Introduction}

Low-temperature solution-processed organic-inorganic halide perovskites have drawn worldwide attention due to their remarkable performance in photovoltaic devices. ${ }^{[1-11]}$ The high energy conversion efficiency is attributed to their long carrier lifetimes ${ }^{[12-15]}$ and high photoluminescence efficiencies ${ }^{[15]}$ of the hybrid perovskites. Recently, the materials also demonstrate interesting light-emitting properties. They exhibit amplified spontaneous light emission with low thresholds, ${ }^{[16]}$ optically pump lasing, ${ }^{[17]}$ and bright electroluminescence (EL) in perovskite light-emitting diodes (LEDs). ${ }^{[18,19]}$ Organic-inorganic halide perovskites generate high color purity (full width at half maximum $\approx 30 \mathrm{~nm}$ ) light. Also, the emission spectrum can be easily tuned from near-infrared to visible and ultraviolet by adjusting the bandgap with substitution of metal cations, ${ }^{[20]}$ halide anions, ${ }^{[18,19]}$ or organic ligands. ${ }^{[21]}$ Therefore, the progress suggests a potential development of this unique class of materials into efficient, high color-purity and color-tunable light emitters for low-cost display, lighting, and optical communication applications. Perovskite LEDs require multiple layers, some of them processed by evaporation under high vacuum conditions. ${ }^{[19,22]}$ Air-sensitive low work-function metals or electron injecting layers are needed for efficient charge carrier injection in the devices. ${ }^{[23]}$ For example, $\mathrm{Ca}, \mathrm{Al}$, and $\mathrm{Ag}$ were commonly used as cathode in perovskite LEDs. However, $\mathrm{Ca}$ is highly chemically active, while $\mathrm{Al}$ and $\mathrm{Ag}$ also react with halide perovskites. ${ }^{[24]}$

Light-emitting electrochemical cells (LECs) are one of the simplest kinds of EL devices, ${ }^{[25]}$ which are formed from just one active layer containing an emitter with ionic conductivity. ${ }^{[26]}$ Light-emitting polymers mixed with solid electrolyte ${ }^{[27-29]}$ and ionic transition-metal small-molecular complexes ${ }^{[30,31]}$ are representative LEC materials. LECs operate at low bias voltages, which achieve high power efficiencies, and allow for high work function air-stable electrodes. ${ }^{[32]}$ The movement of the ions in the active layer under an applied bias allows for efficient electron injection from high work function electrodes.

In this work, we demonstrated perovskite light-emitting devices with two high work function electrodes. Interestingly,

DOI: 10.1002/adfm.201502962 
under both forward and reverse biases, $\mathrm{CH}_{3} \mathrm{CH}_{3} \mathrm{PbI}_{3}\left(\mathrm{MAPbI}_{3}\right)$ perovskite light-emitting devices show infrared EL emission, which can also be demonstrated in $\mathrm{CH}_{3} \mathrm{CH}_{3} \mathrm{PbBr}_{3}\left(\mathrm{MAPbBr}_{3}\right)$ light-emitting devices with green color EL. The impedance spectroscopy indicates that the ionic conductivity in $\mathrm{MAPbI}_{3}$ is very large with a value of $\approx 10^{-8} \mathrm{~S} \mathrm{~cm}^{-1}$, which unambiguously show that the perovskite $\mathrm{MAPbI}_{3}$ is a solid electrolyte with mixed ionic and electronic conductivity. In addition, there is a shift in the emission spectrum in $\mathrm{MAPbI}_{3-x} \mathrm{Br}_{x}$ light-emitting device by changing bias, indicating that $\mathrm{I}^{-}$ions are mobile in the perovskites. The results confirm that the devices are LECs. Consequently, the work suggests that the organic-inorganic halide perovskites are potential electrochemical energy-storage materials, which may be applicable in the field of solid-state supercapacitors and batteries.

\section{Results and Discussion}

\subsection{EL Properties of the lodide Perovskite Light-Emitting Devices}

Light-emitting devices have a structure of perovskite $\mathrm{MAPbI}_{3}$ sandwiched between two high work function electrodes of
ITO/PEDOT:PSS and $\mathrm{MoO}_{3} / \mathrm{Au}$ ) (Figure 1A), with work function of 5.0 and $5.3 \mathrm{eV}$, respectively (Figure $1 \mathrm{~B}$ ). Light emission from the device at forward and reverse biases with the same EL spectra are observed as shown in Figure 2A. The emission of the iodide perovskite device is in the infrared region, with a peak at $761 \mathrm{~nm}$ and infrared radiance reaching $0.23 \mathrm{~W} \mathrm{sr}^{-1} \mathrm{~m}^{-2}$ at the voltage of $2.0 \mathrm{~V}\left(\mathrm{MoO}_{3} / \mathrm{Au}\right.$ is defined as the ground). The current density-voltage $(J-V)$ curve (Figure 2B) shows symmetrical feature at forward and reverse biases, apparently violating the asymmetric conductance of conventional diodes. The threshold voltage for detection of light emission (Figure 2B) is $\approx 1.5 \mathrm{~V}$ for both forward-biased and reverse-biased scans. This turn-on voltage is close (in value) to the perovskite bandgap $(1.5-1.6 \mathrm{eV})$. The abovementioned features are typical behavior of LECs, ${ }^{[27]}$ which implies that the perovskite is a mixed electronic and ionic conductor.

\subsection{Ionic Conduction Properties of the lodide Perovskite}

Impedance spectroscopy was used to distinguish the electronic and ionic components of conductivity in mixed conductors. ${ }^{[33]}$ Figure $3 \mathrm{~A}$ inset shows the equivalent circuit of the mixed conductor in the ITO/PEDOT:PSS/MAPbI $3 / \mathrm{Au}$ device. The
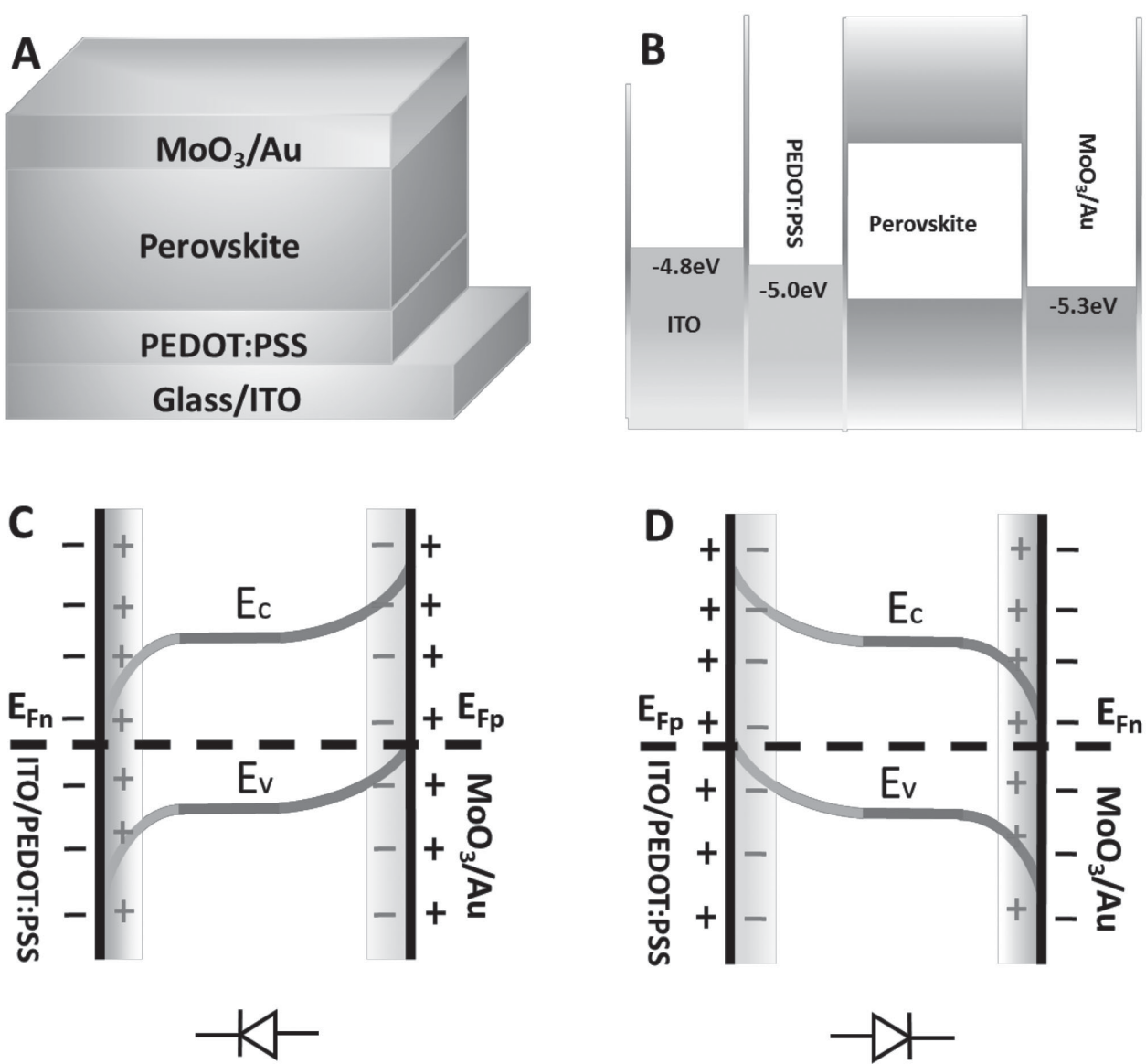

Figure 1. Device structure, energy level diagram, and the mechanism of the perovskite LECs. A) Device structure. B) Energy-level diagram of the materials. C) The device is a forward diode because of positive charge near the ITO/PEDOT:PSS electrode. D) The device is a reversed diode because of positive charge near the $\mathrm{MoO}_{3} / \mathrm{Au}$ electrode. Interface charge and screen charge are represented in grey and black, respectively. 

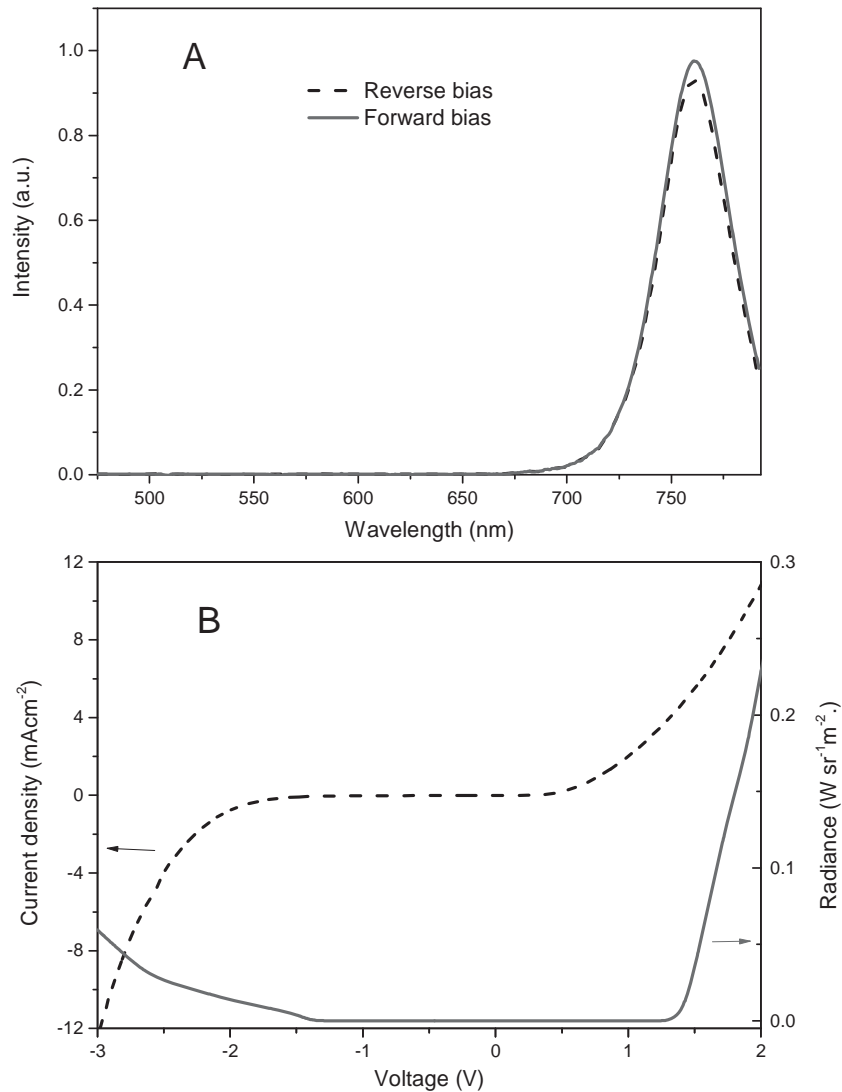

Figure 2. EL properties of the iodide perovskite light-emitting devices. A) EL spectra of the device under forward and backward bias. B) Currentvoltage and radiance-voltage characteristics of the device.

electrodes in this device are ionically blocking but electronically conducting. Therefore, three parallel paths in the circuit are present. $R_{\mathrm{e}}$ is the resistance of the electronic-conducting path, $R_{\mathrm{i}}$ is the resistance of the ionic-conducting path, and $C_{\mathrm{i}}$ is the capacitance from the blocking of ions at the electrode interfaces. $C_{\mathrm{i}}$ represents the combined capacitive properties of the two electrolyte/electrode interfaces. $C_{\mathrm{g}}$ is the geometrical capacitance.

Figure 3A shows the Nyquist plot of the impedance spectra of the device at various temperatures. The curves with two adjacent semicircles on the complex impedance plane are typical behavior of solid electrolytes with mixed ionic and electronic conductivity. $R_{\mathrm{e}}$ and $R_{\mathrm{i}}$ determine the size of the semicircles (Figure S1, Supporting Information). The decrease in circle size with increasing temperature indicates that the conductivities increase at higher temperature. The ionic conductivity, electronic conductivity, and ionic transport number, which is the ratio of ionic conductivity and total conductivity, are calculated according to the size of the semicircles (see the Supporting Information) and summarized in Table 1. The ionic conductivity in $\mathrm{MAPbI}_{3}$ is in the order of $10^{-8} \mathrm{~S} \mathrm{~cm}^{-1}$, which is comparable with that in polymer electrolytes. ${ }^{[34]}$ The ionic transport number is $\approx 0.8$, which indicates that the ionic component dominates the conductivity.

Figure 3B shows the Arrhenius plot of the ionic conductivity at different temperatures. The slope of the plot indicates
Table 1. A summary of the ionic conductivity, electronic conductivity, and the ionic transport number of $\mathrm{MAPbl}_{3}$ at different temperatures.

\begin{tabular}{lccc}
\hline $\begin{array}{l}\text { Temperature } T \\
{\left[{ }^{\circ} \mathrm{C}\right]}\end{array}$ & $\begin{array}{c}\text { Ionic conductivity } \\
\left(\times 10^{-9}\left[\mathrm{~S} \mathrm{~cm}^{-1}\right]\right)\end{array}$ & $\begin{array}{c}\text { Electronic conductivity } \sigma_{\mathrm{e}} \\
\left(\times 10^{-9}\left[\mathrm{~S} \mathrm{~cm}^{-1}\right]\right)\end{array}$ & $\begin{array}{c}\text { Ionic transport } \\
\text { number } t_{\mathrm{i}}\end{array}$ \\
\hline 20 & 4.2 & 1.3 & 0.76 \\
48 & 14 & 2.2 & 0.87 \\
57 & 19 & 3.1 & 0.86 \\
67 & 30 & 4.7 & 0.87 \\
78 & 47 & 8.0 & 0.86 \\
87 & 68 & 12 & 0.84 \\
\hline
\end{tabular}

that the activation energy of mobile ions in $\mathrm{MAPbI}_{3}$ is $0.30 \mathrm{eV}$, which is very close to the activation energy for the migration of the vacancy of halide ions $(0.29 \mathrm{eV})$ in inorganic halide perovskite $\left(\mathrm{CsPbCI}_{3}\right) \cdot{ }^{[35]}$

A certain bias (e.g., 1.0 V) was applied on the device for a period of time $(\approx 15 \mathrm{~s})$ under dark condition to accumulate the ions; in other words, to charge $C_{\mathrm{i}}$. The device was then rapidly switched to zero bias to measure the discharge current (Figure 3C, inset). The accumulated charge density at the bias $(1.0 \mathrm{~V})$ is the time integral of the discharge current. Figure $3 \mathrm{C}$ shows the measured charge densities of the accumulated ions at the interfaces under various biases. The slope of the curve indicates $C_{\mathrm{i}}$ value of $\approx 100 \mu \mathrm{F} \mathrm{cm} \mathrm{cm}^{-2}$. This large areal capacitance exceeds that of conventional electrostatic capacitors ${ }^{[36]}$ with a typical value of $0.1 \mu \mathrm{F} \mathrm{cm} \mathrm{cm}^{-2}$, which is understandable because $C_{\mathrm{i}}$ is the capacitance between the solid perovskite electrolyte and the electrodes. The results suggest a potential application as solid-state supercapacitors by using the organic-inorganic perovskites. In the state-of-the-art supercapacitor design, ${ }^{[37]}$ the conducting materials that have extremely large surface area, such as carbon nanotube or graphene, are used as electrodes. The surface area $\mathrm{S}$ of the electrode material can reach $\approx 1000 \mathrm{~m}^{2} \mathrm{~g}^{-1}$. ${ }^{[38]}$ This could lead to a specific capacitance of $C_{\mathrm{s}}$ $=S C_{\mathrm{i}}=1000 \mathrm{~F} \mathrm{~g}^{-1}$ by using the perovskite material as the solid electrolyte, which is an attractive value for solid-state supercapacitors. However, great effort is still needed to improve the ionic conductivity and the ionic transport number (to unity) before making feasible devices.

The accumulation and relaxation of the interface charge are respectively the charge and discharge processes of $C_{\mathrm{i}}$. Therefore, the $R C$ constant of the ionic-conducting path, $R_{\mathrm{i}} C_{\mathrm{i}}$, governs the dynamics of the interface charge. For example, at the temperature of $20^{\circ} \mathrm{C}, \sigma_{\mathrm{i}}=4.2 \times 10^{-9} \mathrm{~S} \mathrm{~cm}^{-1}$, using a thickness of $L=400 \mathrm{~nm}$, and a capacitance of $C_{\mathrm{i}}=100 \mu \mathrm{F} \mathrm{cm}{ }^{-2}$, then the time constant will be $R_{\mathrm{i}} C_{\mathrm{i}}=C_{\mathrm{i}} L / \sigma_{\mathrm{i}} \approx 1.0 \mathrm{~s}$, which explains the time scale (in the range of seconds) of the discharge process as indicated in Figure 3D. The figure also shows the discharge process at different temperatures. Apparently, higher temperature leads to faster discharge because of the increased ionic conductivity and thus smaller $R C$ constant at higher temperature.

The above results unambiguously indicate that the perovskite $\mathrm{MAPbI}_{3}$ is a solid electrolyte with mixed ionic and electronic conductivity and thus confirm that the iodide perovskite light-emitting device is LEC. The accumulated ions at the interfaces change the band bending of the semiconductor and 

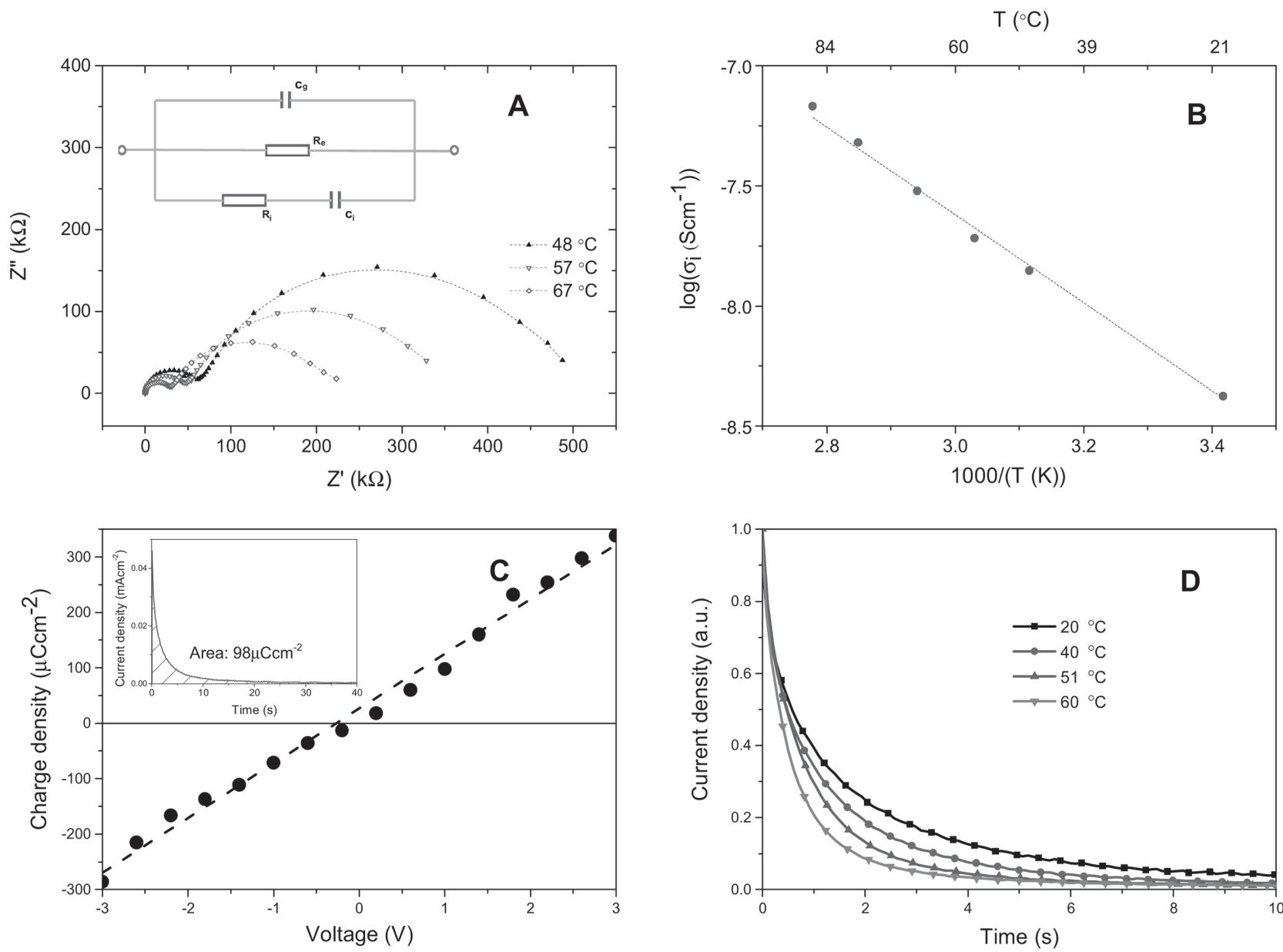

Figure 3. Ionic behaviors of the perovskite MAPb|3. A) Nyquist plot of the impedance spectra at different temperatures. The inset shows the equivalent circuit. B) lonic conductivity as a function of temperature. C) Measured interface charge density at various biases. D) The dynamics of the discharge process at different temperatures.

lead to polarity-switchable diodes (Figure 1C,D) which explains the EL at forward and reverse biases. The responsive time of the LECs is in the range of seconds (Figure S5, Supporting Information).

Since the results show that organic-inorganic perovskites are solid electrolyte, a device with the structure of electrode (1)/perovskite/electrode (2) can function as an electrochemical cell, suggesting that it is possible to measure the open-circuit electromotive force (EMF) in the cells with different electrode potentials. ${ }^{[35]}$ We observed significant EMF in the device of ITO/PEDOT:PSS/MAPbI $3 /$ PCBM/Au. Right after the device fabrication, we measured the open-circuit EMF (voltage) of the device under dark condition. Figure 4A shows the measured EMF of the device at various temperatures. Figure 4B shows the observed EMF and the short-circuit current of the device at room temperature under dark condition. The device shows significant EMF of $\approx 0.5 \mathrm{~V}$ and the apparent dark shortcircuit current of $\approx 0.04 \mu \mathrm{A} \mathrm{cm}{ }^{-2}$. It is interesting to note that besides the report of the perovskite device of ITO/PEDOT:PSS/ $\mathrm{MAPbI} / \mathrm{PCBM} / \mathrm{Au}$ as an efficient solar cell and light-emitting diode, the result of EMF indicates that perovskite device can work as a battery.

\subsection{Shift of Emission Spectrum and Ion Migration of Mixed Bromide-lodide Perovskite LECs}

LECs are fabricated to obtain the light emission in visible range by using $\mathrm{MAPbBr}_{3}$ and $\mathrm{MAPbI}_{3-x} \mathrm{Br}_{x}$ as emitters. The emission from the LECs of ITO/PEDOT:PSS $(30 \mathrm{~nm}) / \mathrm{MAPbBr}_{3}$ $(400 \mathrm{~nm}) / \mathrm{MoO}_{3}(8 \mathrm{~nm}) / \mathrm{Au}$ is green, with the emission peak at $532 \mathrm{~nm}$ (Figure 5A). The turn-on voltage of the device is $2.4 \mathrm{~V}$, which corresponds to the bandgap $(\approx 2.4 \mathrm{eV})$ of the bromide perovskite.

The EL spectra of the mixed iodide-bromide perovskite LECs of ITO/PEDOT:PSS/MAPbI ${ }_{3-x} \mathrm{Br}_{3}(400 \mathrm{~nm}) / \mathrm{MoO}_{3} / \mathrm{Au}$ are tunable with the applied voltage (Figure $5 \mathrm{~B}$ ). At $2.0 \mathrm{~V}$, the emission peaks at $743 \mathrm{~nm}$, which is consistent with the photoluminescent (PL) spectrum of the mixed perovskite film with I-to-Br molar ratio of 4:9 (Figure 5C). When the voltage is increased, the peak continuously broadens at its shorter wavelength up to $5.0 \mathrm{~V}$, and eventually shifts to $710 \mathrm{~nm}$ at $7.0 \mathrm{~V}$. Another emission peak at $532 \mathrm{~nm}$ (the same peak as $\mathrm{MAPbBr}_{3}$ ) appears at $5.0 \mathrm{~V}$ and becomes evidently pronounced at higher voltage.

The absorption and PL spectra of the materials with various I-to- $\mathrm{Br}$ ratios are investigated to understand the spectra shift. 

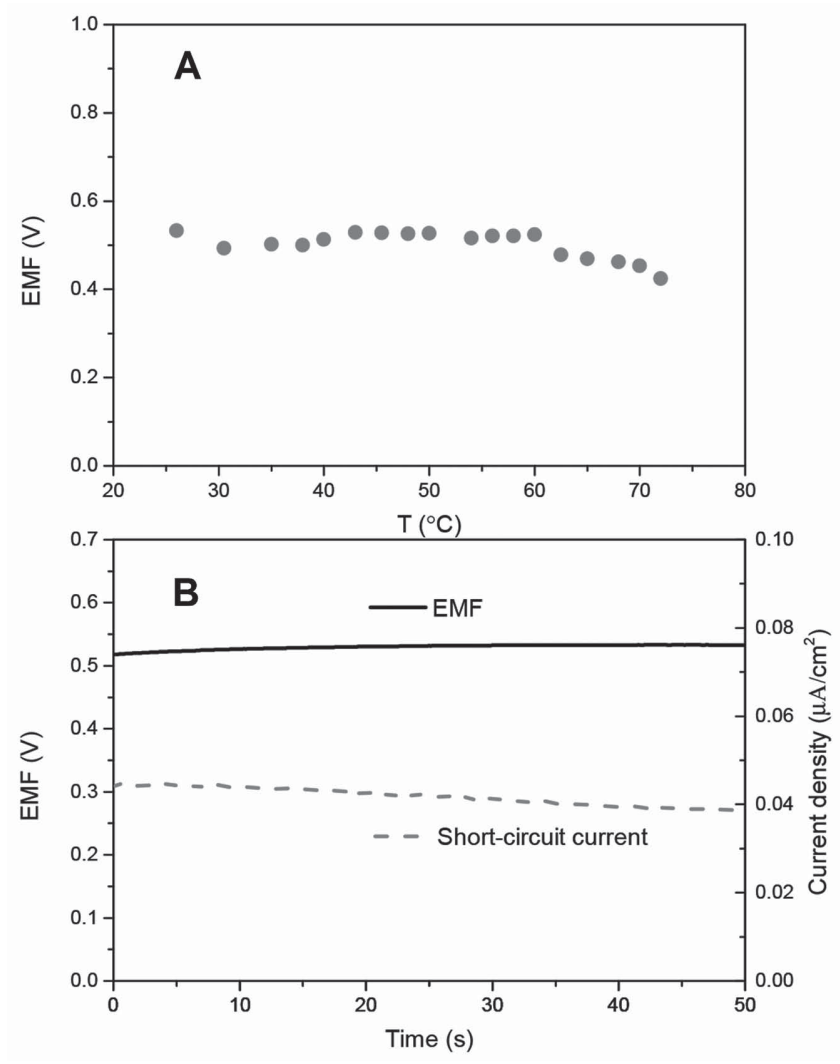

Figure 4. Electromotive force and the short-circuit current of the device ITO/PEDOT:PSS/MAPb| $3 / \mathrm{PCBM} / \mathrm{Au}$ under dark condition. A) Electromotive force at various temperatures. B) Electromotive force and short-circuit current at room temperature.

The bandgap (Figure S3C, Supporting Information) and the PL emission (Figure 5C) of the mixed perovskite are continuously tunable with the I-to- $\mathrm{Br}$ ratio. At the I-to- $\mathrm{Br}$ ratio of $4: 9$, the PL emission peaks at $743 \mathrm{~nm}$, which is consistent with the EL emission of the LECs at $2.0 \mathrm{~V}$ (Figure 5B). However, when the I-toBr ratio decreases from 4:9 to 1:9, the PL emission peak shifts from 743 to $710 \mathrm{~nm}$. This trend is similar to the peak shift in the LECs with increasing bias, implying that the spectra shift of the mixed perovskite LECs is due to the compositional change of the material in emission zone. At higher voltage, the I-to-Br ratio becomes lower and even iodine-free in some parts. Thus, this phenomenon leads to the blue shift of the emission in the infrared range and the appearance of the $532 \mathrm{~nm}$ emission band, which suggests that the halide ions, especially I- ions, are mobile in the perovskites. Under low bias, limited number of ions migrates to the interfaces. However, at higher bias, more ions, especially $\mathrm{I}^{-}$ions, drift toward the interface region, leading to the composition (I-to-Br ratio) change in the middle emission zone and thus the EL spectra shift (Figure S4, Supporting Information).

This hypothesis is further confirmed by examining the EL spectra of the mixed perovskite in a different ITO/PEDOT:PSS/ $\mathrm{MAPbI}_{3-x} \mathrm{Br}_{x}\left(\mathrm{MAI}-40 \mathrm{mg} \mathrm{mL}^{-1}\right) / \mathrm{PCBM} / \mathrm{Au}$ device (Figure 5D). In this device, a thick PCBM layer $(90 \mathrm{~nm})$ was inserted between the perovskite and the Au electrode. As a consequence, significantly lower interface charge was observed, ${ }^{[39]}$ compared with the former mixed perovskite LECs (Figure S2, Supporting Information). This result indicates that at the same voltage, fewer ions migrate to the interface of the device. In contrast to the radical change in EL spectra in the former LECs, the peak shift in this device is very limited (from 745 to $742 \mathrm{~nm}$ ), and no appearance of the $532 \mathrm{~nm}$ peak was observed when the bias was increased from 2.0 to $6.0 \mathrm{~V}$. Therefore, the halide ions, especially $\mathrm{I}^{-}$ions, are mobile in the perovskite, and the spectra shift reflects the change in composition (I-to$\mathrm{Br}$ ratio) of the mixed perovskites under different biases. This result agrees with the theoretical one of $\mathrm{MAPbI}_{3}$ determined by density functional theory recently ${ }^{[40]}$ and previous experimental finding that ionic conduction is caused by the migration of halide-ion vacancies (Figure S6, Supporting Information) in inorganic halide perovskites ${ }^{[35]}$ and in organic-inorganic halide perovskite $\mathrm{CH}_{3} \mathrm{NH}_{3} \mathrm{GeCl}_{3} \cdot{ }^{[41]}$

\section{Conclusions}

In this work, we demonstrate EL of perovskite light-emitting devices with two high work function electrodes under both forward and reverse biases. The shift of emission spectrum of $\mathrm{MAPbI}_{3-x} \mathrm{Br}_{x}$ perovskite light-emitting device indicates that $\mathrm{I}^{-}$ions move in the perovskite during operation. Meanwhile, the results of impedance spectroscopy indicate that $\mathrm{MAPbI}_{3}$ is a solid electrolyte with mixed ionic and electronic conductivity. The ionic conductivity in $\mathrm{MAPbI}_{3}$ is $\approx 10^{-8} \mathrm{~S} \mathrm{~cm}^{-1}$, and the ionic transport number is $\approx 0.8$. The activation energy for the migration of ions in the organic-inorganic halide perovskite is $0.30 \mathrm{eV}$. We also observed significant electromotive force in perovskite devices. The results confirm that the perovskite light-emitting devices with two high work function electrodes are LECs. The extremely simple device structure and the use of high work function electrode further strengthen the potential of developing the organic-inorganic perovskite into efficient, high color-purity and color-tunable light emitters for low-cost display, lighting, and optical communication applications.

In addition, the above results suggest new applications for organic-inorganic halide perovskites. Besides the demonstrated light-emitting electrochemical device, the significant ionic conductivity also suggests the potential application of electrochemical energy-storage devices, ${ }^{[42]}$ such as solid-state supercapacitors and batteries. The observed large capacitance $\left(\approx 100 \mu \mathrm{F} \mathrm{cm}^{-2}\right)$ and the significant EMF of perovskite devices support this suggestion. Therefore, it is possible to build an integrated device including photovoltaic energy harvesting, energy storage, and light-emitting subparts all from organicinorganic perovskites.

\section{Experimental Section}

$\mathrm{Pbl}_{2}$ and $\mathrm{PbBr}_{2}$ were dissolved in DMF $\left(1 \mathrm{M}\right.$ ) and $\mathrm{CH}_{3} \mathrm{NH}_{3} \mathrm{I}$ (MAI) was dissolved in 2-propanol. To ensure MAl, $\mathrm{PbBr}_{2}$, and $\mathrm{Pbl}_{2}$ were fully dissolved, both solutions were heated at $70{ }^{\circ} \mathrm{C}$ for $30 \mathrm{~min}$ before use. The device architecture were ITO/PEDOT:PSS $(30 \mathrm{~nm}) / \mathrm{MAPbl}_{3}$ $(400 \mathrm{~nm}) / \mathrm{Au}, \quad$ ITO/PEDOT:PSS $(30 \mathrm{~nm}) / \mathrm{MAPbl}_{3}(400 \mathrm{~nm}) / \mathrm{MoO}_{3}$ $(8 \mathrm{~nm}) / \mathrm{Au}$, and ITO/PEDOT:PSS $(30 \mathrm{~nm}) / \mathrm{MAPbl}_{3-x} \mathrm{Br}_{x}(400 \mathrm{~nm}) / \mathrm{MoO}_{3}$ $(8 \mathrm{~nm}) / \mathrm{Au}$. The active area is $0.038 \mathrm{~cm}^{2}$. PEDOT:PSS (Baytron-P4083) 


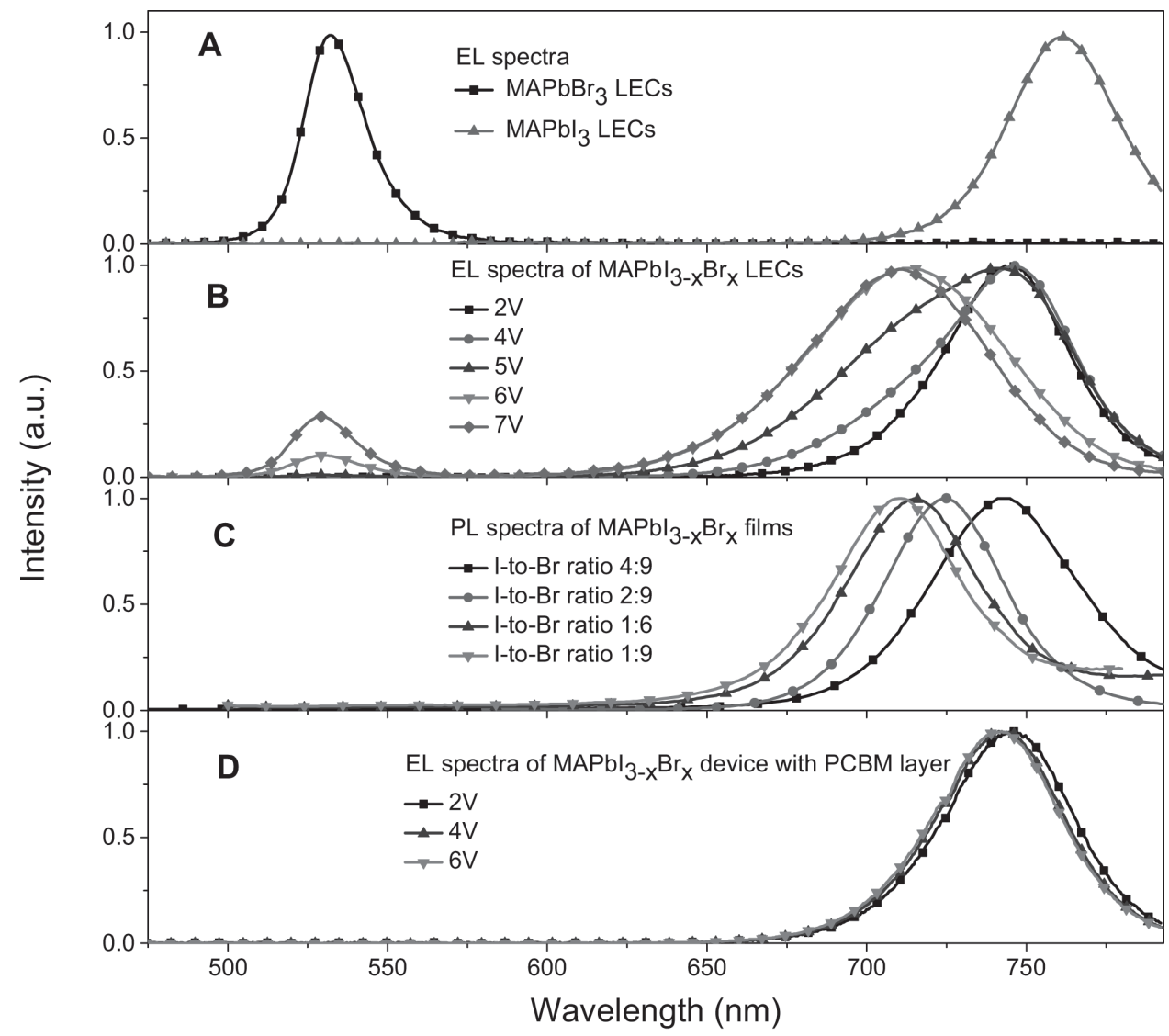

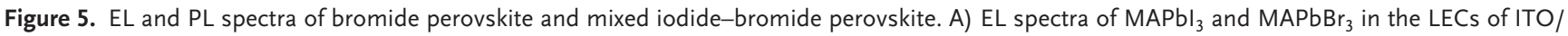
PEDOT:PSS/Perovskite/MoO $/$ Au. B) EL spectra of the mixed perovskite $\mathrm{MAPbl}_{3-x} \mathrm{Br}_{x}$ in the LECs of ITO/PEDOT:PSS/Perovskite/MoO $/ \mathrm{Au}_{3}$ at different biases. C) PL spectra of the mixed perovskite $\mathrm{MAPbl}_{3-x} \mathrm{Br}_{x}$ with different I-to- $\mathrm{Br}$ ratios. D) EL spectra of the mixed perovskite $\mathrm{MAPbl}_{3-x} \mathrm{Br}_{x}$ in the device ITO/PEDOT:PSS/Perovskite/PCBM/Au at different biases.

was spin-cast onto the clean surface of the ITO substrates at $4000 \mathrm{rpm}$ for $40 \mathrm{~s}$ and then thermally annealed on a hot plate at $120^{\circ} \mathrm{C}$ for $30 \mathrm{~min}$ in air. In a nitrogen-filled glove box, the solution of $\mathrm{Pbl}_{2}$ was spin-coated onto the PEDOT:PSS layer at $4000 \mathrm{rpm}$ for $15 \mathrm{~s}$ and then annealed at $70{ }^{\circ} \mathrm{C}$ for $15 \mathrm{~min}$. After drying, the MAl solution in 2-propanol $\left(20 \mathrm{mg} \mathrm{mL}^{-1}\right.$ ) was spin-coated onto the $\mathrm{Pbl}_{2}$ layer at $3000 \mathrm{rpm}$ for $5 \mathrm{~s}$ and then annealed at $70{ }^{\circ} \mathrm{C}$ for $30 \mathrm{~min}$ to form the perovskite $\mathrm{MAPbl}_{3}$. The solution of $\mathrm{PbBr}_{2}$ was spin-coated onto the PEDOT:PSS layer at $4000 \mathrm{rpm}$ for $15 \mathrm{~s}$ and then annealed at $70^{\circ} \mathrm{C}$ for $15 \mathrm{~min}$. After drying, the MAI solution with different concentration in 2-propanol $\left(40 \mathrm{mg} \mathrm{mL}^{-1}\right)$ was spin-coated onto the $\mathrm{PbBr} 2$ layer at $3000 \mathrm{rpm}$ for $5 \mathrm{~s}$ and then annealed at $70{ }^{\circ} \mathrm{C}$ for $30 \mathrm{~min}$ to form the perovskite $\mathrm{MAPbl}_{3-x} \mathrm{Br}_{x}$. $\mathrm{PC}_{61} \mathrm{BM}$ (in chlorobenzene) was then spin-coated onto the perovskite layer at $3000 \mathrm{rpm}$ for $40 \mathrm{~s}$. Finally, the samples were moved into a vacuum chamber for $\mathrm{MoO}_{3}$ and gold deposition. The thickness of the $\mathrm{MoO}_{3}$ and gold are 8 and $80 \mathrm{~nm}$, respectively. The thickness of the perovskite is $\approx 400 \mathrm{~nm}$, as measured with an Ambios XP-2 profilometer. The $J-V$ characteristics were recorded by a Keithley (and Agilent) source meter under dark condition. The PL spectra of the perovskite films were recorded by a Fluorolog-3 fluorescence spectrometer. The EL spectra were recorded by an Acton Insectrum CCD spectrometer. The radiance of the infrared emission was measured with a Newport Optical Power Meter. Impedance spectroscopy was conducted on a Zahner Zennium electrochemical workstation. The impedance spectra were measured under a small $A C$ signal with an amplitude of $20 \mathrm{mV}$ at the bias of $0 \mathrm{~V}$ under dark condition. The detailed method to calculate the ionic conductivity, the electronic conductivity, and the ionic transport number is available in the Supporting Information.

\section{Supporting Information}

Supporting Information is available from the Wiley Online Library or from the author.

\section{Acknowledgements}

The authors thank Prof. Xiqiang Huang for the enlightening discussion on the result of impedance spectroscopy. This work was supported from the National Natural Science Foundation of China (Grant Nos. 61574014,11474017, 21174016, and 60776039), the Research Fund for the Doctoral Program of Higher Education of China (Grant No. 20120009110031), and the Fundamental Research Funds for the Central Universities (Grant Nos. 2013/BZ004 and 2013JBM102). W. C. H. Choy acknowledges the financial support of the General Research Fund (Grant No. HKU71 1813), the Collaborative Research Fund (Grant Nos. CUHK1/ CRF/12C and C7045-14E) from the Research Grants Council of Hong Kong, and Grant CAS14601 from CAS-Croucher Funding Scheme for Joint Laboratories.

Received: July 17, 2015

Revised: September 8, 2015

Published online:

[1] A. Kojima, K. Teshima, Y. Shirai, T. Miyasaka, J. Am. Chem. Soc. 2009, 137, 6050 .

[2] D. Liu, T. L. Kelly, Nat. Photon. 2014, 8, 133. 
[3] H. Zhou, Q. Chen, G. Li, S. Luo, T. B. Song, H. S. Duan, Z. Hong, I. You, Y. Liu, Y. Yang, Science 2014, 345, 542.

[4] S. Sun, T. Salim, N. Mathews, M. Duchamp, C. Boothroyd, G. Xing, T. C. Sum, Y. M. Lam, Energy Environ. Sci. 2014, 7, 399.

[5] Z. Xiao, C. Bi, Y. Shao, Q. Dong, Q. Wang, Y. Yuan, C. Wang, Y. Gao, J. Huang, Energy Environ. Sci. 2014, 7, 2619.

[6] S. Ryu, J. H. Noh, N. J. Jeon, Y. C. Kim, S. Yang, J. W. Seo, S. I. Seok, Energy Environ. Sci. 2014, 7, 2614.

[7] B. Conings, L. Baeten, C. De Dobbelaere, J. D'Haen, J. Manca, H.-G. Boyen, Adv. Mater. 2014, 26, 2041.

[8] J. You, Z. Hong, Y. Yang, Q. Chen, M. Cai, T.-B. Song, C.-C. Chen, S. Lu, Y. Liu, H. Zhou, Y. Yang, ACS Nano 2014, 8, 1674.

[9] J.-Y. Jeng, K.-C. Chen, T.-Y. Chiang, P.-Y. Lin, T.-D. Tsai, Y.-C. Chang, T.-F. Guo, P. Chen, T.-C. Wen, Y.-J. Hsu, Adv. Mater. 2014, 26, 4107.

[10] F. X. Xie, D. Zhang, H. Su, X. Ren, K. S. Wong, M. Grätzel, W. C. H. Choy, ACS Nano 2015, 9, 639.

[11] W. E. I. Sha, X. Ren, L. Chen, W. C. H. Choy, Appl. Phys. Lett. 2015, 106, 221104.

[12] S. D. Stranks, G. E. Eperon, G. Grancini, C. Menelaou, M. J. Alcocer, T. Leijtens, L. M. Herz, A. Petrozza, H. J. Snaith, Science 2013, $342,341$.

[13] G. Xing, N. Mathews, S. Sun, S. S. Lim, Y. M. Lam, M. Gratzel, S. Mhaisalkar, T. C. Sum, Science 2013, 342, 344.

[14] D. Li, C. Liang, H. Zhang, C. Zhang, F. You, Z. He, J. Appl. Phys. 2015, 117, 074901.

[15] D. W. de Quilettes, S. M. Vorpahl, S. D. Stranks, H. Nagaoka, G. E. Eperon, M. E. Ziffer, H. J. Snaith, D. S. Ginger, Science 2015, $348,683$.

[16] G. Xing, N. Mathews, S. S. Lim, N. Yantara, X. Liu, D. Sabba, M. Gratzel, S. Mhaisalkar, T. C. Sum, Nat. Mater. 2014, 13, 476.

[17] F. Deschler, M. Price, S. Pathak, L. E. Klintberg, D.-D. Jarausch, R. Higler, S. Hüttner, T. Leijtens, S. D. Stranks, H. J. Snaith, M. Atatüre, R. T. Phillips, R. H. Friend, J. Phys. Chem. Lett. 2014, 5, 1421.

[18] Z.-K. Tan, R. S. Moghaddam, M. L. Lai, P. Docampo, R. Higler, F. Deschler, M. Price, A. Sadhanala, L. M. Pazos, D. Credgington, F. Hanusch, T. Bein, H. J. Snaith, R. H. Friend, Nat. Nanotechnol. 2014, 9, 687.
[19] Y. H. Kim, H. Cho, J. H. Heo, T. S. Kim, N. Myoung, C. L. Lee, S. H. Im, T. W. Lee, Adv. Mater. 2015, 27, 1248.

[20] F. Hao, C. C. Stoumpos, D. H. Cao, R. P. H. Chang, M. G. Kanatzidis, Nat. Photon. 2014, 8, 489

[21] N. J. Jeon, J. H. Noh, W. S. Yang, Y. C. Kim, S. Ryu, J. Seo, S. I. Seok, Nature 2015, 517, 476

[22] X. Qin, H. Dong, W. Hu, Sci. China Mater. 2015, 58, 186.

[23] G. Li, Z. K. Tan, D. Di, M. L. Lai, L. Jiang, J. H. Lim, R. H. Friend, N. C. Greenham, Nano Lett. 2015, 15, 2640.

[24] Z. Xiao, Y. Yuan, Y. Shao, Q. Wang, Q. Dong, C. Bi, P. Sharma, A. Gruverman, J. Huang, Nat. Mater. 2015, 14, 193.

[25] A. Sandstrom, H. F. Dam, F. C. Krebs, L. Edman, Nat. Commun. 2012, 3, 1002

[26] Z. Yu, L. Li, H. Gao, Q. Pei, Sci. China: Chem. 2013, 56, 1075.

[27] Q. Pei, G. Yu, C. Zhang, Y. Yang, A. J. Heeger, Science 1995, 269, 1086.

[28] J. Gao, J. Dane, Appl. Phys. Lett. 2003, 83, 3027.

[29] X. Li, F. AlTal, G. Liu, J. Gao, Appl. Phys. Lett. 2013, 103, 243304.

[30] J. D. Slinker, J. Rivnay, J. S. Moskowitz, J. B. Parker, S. Bernhard, H. D. Abruna, G. G. Malliaras, J. Mater. Chem. 2007, 17, 2976.

[31] Y. Shen, D. D. Kuddes, C. A. Naquin, T. W. Hesterberg, C. Kusmierz, B. J. Holliday, J. D. Slinker, Appl. Phys. Lett. 2013, 102, 203305.

[32] S. B. Meier, D. Tordera, A. Pertegás, C. Roldán-Carmona, E. Ortí, H. J. Bolink, Mater. Today 2014, 17, 217.

[33] R. A. Huggins, lonics 2002, 8, 300

[34] Z. Gadjourova, Y. G. Andreev, D. P. Tunstall, P. G. Bruce, Nature $2001,412,520$

[35] J. Mizusaki, K. Arai, K. Fueki, Solid State lonics 1983, 11, 203

[36] P. Sharma, T. S. Bhatti, Energy Convers. Manage. 2010, 51, 2901.

[37] X. Lu, M. Yu, G. Wang, Y. Tong, Y. Li, Energy Environ. Sci. 2014, 7, 2160

[38] J. R. Miller, P. Simon, Interface 2008, 17, 2.

[39] H. Zhang, C. Liang, Y. Zhao, M. Sun, H. Liu, J. Liang, D. Li, F. Zhang, Z. He, Phys. Chem. Chem. Phys. 2015, 17, 9613.

[40] C. Eames, J. M. Frost, P. R. Barnes, B. C. O'Regan, A. Walsh, M. S. Islam, Nat. Commun. 2015, 6, 7497.

[41] K. Yamada, K. Isobe, E. Tsuyama, T. Okuda, Y. Furukawa, Solid State Ionics 1995, 79, 152.

[42] K. Funke, Sci. Technol. Adv. Mater. 2013, 14, 043502. 